\title{
Rural Community Health Needs Assessment Findings: Access to Care and Mental Health
}

\author{
Sabrina T. Cherry \\ University of North Carolina Wilmington \\ Ayanna Robinson \\ University of Georgia \\ Jared Jashinsky \\ University of Georgia \\ Grace Bagwell-Adams \\ University of Georgia \\ Michelle Elliott \\ University of Georgia \\ Marsha Davis \\ University of Georgia
}

\begin{abstract}
This article highlights the qualitative results from focus groups conducted as part of a Community Health Needs Assessments in two rural Georgia communities. Four 1-hr focus groups were facilitated with 32 community stakeholders. Sessions were audio recorded and transcribed verbatim. Thematic analysis identified two primary themes: mental health and barriers to accessing health care. Focus group participants discussed mental health challenges as they related to substance abuse and suicide. Participants acknowledged barriers to access, including no health insurance, cost, eligibility gaps for governmentsponsored programs, the low availability of specialty care, and poverty. Addressing mental health and access to care in rural communities may require alternative, tailored programs.
\end{abstract}

Keywords: community health needs assessment, access to care, mental health, rural health

\section{Introduction}

Research has identified numerous health disparities in rural communities (Befort, Nazir, \& Perri, 2012; Singh \& Siahpush, 2014; Vander Weg, Cunningham, Howren, \& Cai, 2011). In comparison to many communities in U.S. urban cities, rural populations tend to have a high incidence of mental illness, such as depression and substance abuse. These populations also experience limited access to mental health services, may be stigmatized when accessing services, and tend to wait to seek care at severe stages of illness (Smalley et al., 2010). Rural health disparities intersect with other challenges of the southern United States, including a high poverty rate, uninsured individuals, and poor health status (Artiga, 2016). The purpose of this article is to share the qualitative results from a 
Community Health Needs Assessments (CHNAs) that highlight additional challenges in two rural counties in Georgia: mental health and access to care.

From 2009 to 2011, states cut mental health services budgets by $\$ 2.1$ billion in response to the recession (Larrison et al., 2011), resulting in fewer resources for rural areas where state-funded services are often the only available care. Many states increased mental health funding in 20132014's budgets to compensate for cuts, but these increases slowed in 2015-2016 (National Alliance on Mental Illness, 2015). Reduced mental health funding is of particular concern in Georgia. The state was 41st lowest in per capita funding of state mental health agencies in 2013, lower than neighboring Alabama (37th) and Tennessee (35th; Kaiser Family Foundation, 2013). Difficulties caused by reduced state funding for mental health services were compounded when the Patient Protection and Affordable Care Act (ACA) expanded insurance coverage that increased demand for mental health services (Larrison et al., 2011).

Limits on timely appointments, care continuity, and specialty care reduce access to care for individuals in rural areas (Wong \& Regan, 2009). Lack of insurance coverage and health care access are particularly relevant in the southern United States, where most states did not expand Medicaid under the ACA (Garfield, 2016). Georgia has a lower than average ratio of health care providers to population that further limits access to care (Kaiser Family Foundation, 2016). These disparities place rural Georgians at risk for limited access and could worsen as Disproportionate Share Payments, federal subsidies that support higher levels of care to indigent patients, are incrementally reduced in coming years (Mitchell, 2016). Higher health risks and less access to care in rural populations demonstrate a need to understand the unique dynamics in rural areas.

\section{Method}

CHNAs are required by the ACA for 501(c)(3) hospitals and provide regular opportunities to assess the health of rural communities, including mental health and access-to-care disparities (Internal Revenue Service, 2016). This article focuses on the qualitative results of CHNAs for two rural Georgia hospitals in counties with greater health burdens than the rest of the state (Robinson, Cherry, Elliott, Davis, \& Bagwell-Adams, 2016). The larger project from which these data were drawn followed a sequential-explanatory, mixed-methods design. Characteristic of sequential designs, data were collected during two distinct phases, with quantitative data collected first followed by qualitative data collection (Creswell, 2013). Data were initially collected through secondary sources that provided context through county-level statistics on community health behaviors and outcomes. The collection and analysis of secondary data were followed by community surveys and focus groups. The process for conducting the CHNAs is reported in Robinson et al. (2016), and the qualitative methods relevant for this study are detailed below.

The team that completed the 2015-2016 CHNAs for the two rural hospitals was formed through the University of Georgia Archway Partnership. Team members were a researcher and graduate students from the University of Georgia Department of Health Promotion and Behavior, a researcher from the Department of Health Policy and Management, and Public Service faculty members who served as community liaisons for the two counties. 


\section{Data Collection}

Focus groups were conducted as they are particularly well suited for understanding the opinions, behaviors, and perceptions of individuals in communities (Liamputtong, 2011). The purpose of the focus groups was to illuminate survey findings by providing context to variables measured in the survey. The CHNA team used the community survey and past CHNAs from the target areas to develop standardized focus group questions. The final focus group guide broadly explored community assets, resources, and services to address community health problems. Below is a subset of the questions asked during the focus groups that were relevant to the findings presented in this article:

(1) What would you say are the biggest health problems in the community?

(2) What suggestions or recommendations do you have for addressing the health issues you mentioned?

(3) Where does the community usually get health care services when they need it?

(4) What are the biggest barriers that keep people in the community from accessing health care?

(5) What additional services, if any, would you like to see provided at [the local medical center]?

(6) Is there anything we haven't covered in this discussion that you think is important?

The Archway professionals who worked in the CHNA communities recruited a purposive sample of participants to reflect diverse viewpoints from the communities. This was done by contacting a list of potential participants from various community sectors. All invited participants agreed to participate in a focus group. A minimum of two focus groups are suggested to ensure findings are not a reflection of a single group's characteristics. Furthermore, saturation is typically achieved through three to four focus groups per subset of the population under investigation (Hughes \& DuMont, 1993). Four 1-hr focus groups were conducted December 2015 to February 2016 with 32 community members, who lived and worked in the hospitals' service areas. There were three focus groups with 22 community members from the first county and one focus group with 10 community members from the second county. Two graduate students from the University of Georgia facilitated each focus group as moderator and note-taker.

This study was approved by the Institutional Review Board at the university and all participants signed a consent form before participation. A majority of the focus group participants were nonHispanic White $(n=26)$, a slightly higher representation of Whites compared to the county's' demographics. The remaining participants were non-Hispanic Black. There were 18 women participants. The focus group participants represented a diverse range of professions including nurses, business owners, clergy, elementary and middle school staff, one high school student, college students, members of the county commission, members of the county department of recreation, and retirees. In one focus group, participants also included county elected officials. Additional demographic data were not collected.

\section{Data Analysis}

Focus groups were audio recorded and the recordings were transcribed verbatim by researchers at the University of Georgia. Pseudonyms were assigned to all participants. All responses were separated by question and transferred to a data matrix for review and analysis. The analytic approach was driven by the purpose of the focus groups. Researchers first reviewed the responses 
from a group and inductively developed codes for each response. Codes were then organized by category. Finally, the CHNA team used a thematic analysis to identify salient themes that emerged within and between the focus groups as reflected in the codes and categories (Maxwell, 2013). Participant responses brought the experiences and perspectives of community members to the forefront of the discussion.

\section{Results}

Community members conversed at length about mental health and access to care in rural Georgia, including suicide occurrences in their county, substance use, and an inability to address these challenges because of barriers to care. They shared firsthand experiences, as well as the experiences of community members they knew.

\section{Mental Health}

Focus group participants discussed community challenges to care with mental health identified as a major theme: substance abuse and suicide were subthemes. In one county, participants voiced concerns over the number of recent suicides, underscoring the need for better access to mental health services. Elizabeth stated,

It's hard to wrap your arms around somebody who's having a really hard time, whether it be with drugs or depression-emotional problems — that kind of thing ... this community has had some serious problems with suicide and depression and it's awful. It tears families apart so if there [is] more therapy and more support groups-absolutely—for people who may be suicidal or even for families who have dealt with that-that would be helpful. It's not just about physical sickness and physical health problems, there's a lot of mental health and a lot of emotionally sick people around here who need help too.

This comment shed light on community members' sense of inadequacy to address mental health, including how or where to provide referrals. Carolyn highlighted that resources were available for students and staff employed by the elementary, middle, and high schools, "...this year in the school system we have two mental health counselors [who] are a part of a grant from the [local health district]." However, these resources were not available to community members not employed by the school district.

Some focus group participants discussed mental health, substance use, and access to services concurrently. According to Michael,

We lack sufficient mental health care facilities, and mental health care doctors. We pretty much have to go to [another city] to get to a psychologist and that would [apply to] a pediatric psychologist, someone that can treat [them] with the medications to help them then get to the counselors-we have some local counselors but even there...I would say a weakness would be mental health care.

Michael also acknowledged that a history of inadequate care leads to other health challenges. He added, 
many times a person is getting released from our county detention center and they are walking the roads - they don't have a place to go so it all ties in the drugs, the family upbringing, and helping them in any way.

Therefore, access to mental health care and appropriate follow-up are both problematic.

Jan echoed Michael's thoughts: "It's hard to find the psychiatrist; it's one at [a community agency] ... now I think they do the telephone conference. It's very difficult to find psychiatric care. There are several counseling providers but it's harder." In addition to mental health care access, community members identified an absence of rehabilitation or treatment programs as a key challenge to linkages in care for substance use. Felicia noted,

I don't know what ... percentage of folks in jail are there for drug related crimes, but I've often heard it's $80 \%$, so that extraordinarily high. It would be in the minority if you weren't there for that reason-you would be the exception. It's awful to say, but law enforcement and the courts are the treatment programs for drugs because they are the only ones that can enforce treatment. It's challenging.

Felicia highlighted why treatment and rehabilitation programs are essential for healthy communities. Individuals with substance abuse disorders can be linked to care, provided with adequate follow-up, and ideally, offered assistance to deter them from criminal activity.

While discussing the repercussions of mental health, substance abuse, and the criminal justice system, a community member shared how individuals with mental health concerns are often managed by law enforcement. Limited mental health resources mean cases go unmanaged until problems arise. Fred commented,

Overall mental health [care] is something lacking in the state of Georgia. If you really want to know how that works you know, talk to any sheriff in any county, and he's going to tell you that he is managing a majority of mental health cases in his district because they really don't have any place to go. So when someone is having problems or they're having issues, where do they end up? They end up in the county jail. It pulls a lot of funds out of the county and otherwise. That's something that the state is going to have to fix.

Fred further emphasized what other participants stated: "When there are no or too few services to access, law enforcement must respond to mental health disorders as criminal activities, rather than opportunities to link people to treatment and rehabilitation services."

For communities without resources, alternative means to address mental health may be useful. Though participants reported mental health resources are limited in their areas, Joseph spoke of a mental health group that set up a resource for children in the school system:

They're set up in the school systems. We didn't have to pay for anything, but just had a place for them to set up. If the kid got an issue, I don't think they can [provide] medication, but they can refer them to other places...This organization from [the local university] helps set these different things up in our school systems, so at least the kids got a chance to go to a doctor. 
This section highlights community perspectives on addressing mental health in a rural community. Participants emphasized they would like to see more support services for individuals and families coping with mental health challenges, including an increase in mental health practitioners.

\section{Barriers to Access}

When considering recommendations to improve access, focus group participants acknowledged barriers, including poverty and difficulty accessing specialty care. Participants from each focus group discussed traveling to neighboring counties for dental, mental health, or pediatric services. Community members reported a wide range of financial barriers despite the ACA. Barriers included lack of health insurance, high care and medication costs, and eligibility gaps for governmentsponsored programs. Josie stated,

You often hear about the ones in the gap-folks who are on Medicaid and PeachCare for children. I think they have that access as far as costs—no cost or low-cost—but folks that don't qualify for those programs, but still are not wealthy and don't have resources to pay the $\$ 50$ deductible for each visit or something is perhaps ones that are most affected by cost.

Holland added,

I know that in the Part D plan when they hit the coverage gap, what they call the doughnut hole, we'd have quite a few that kind of suffer because they have to pay the full price of the medicine until they hit that next level and that's kind of been a problem.

For Josie and Holland, social service programs, such as copay assistance and Medicare are valuable to pay for coverage, but these programs do not cover individuals who fall in the coverage or income gaps.

For individuals who need medical care and cannot afford it, the emergency department is often used as a primary care office. Concerning persons who are uninsured or underinsured using the emergency department, Dan stated,

It was like on a Friday night and it was full of people ... that were there for basically urgent care. Not any real emergency, you know ... Where do you go if you don't have a family physician, you don't have a regular doctor? So if your child gets sick, you're going to take them to the emergency room. Even though it may not be an emergency, but that's the only place you got to go.

Participants stressed financial assistance was a significant need for many groups in the county. Rashon said, "One of the greatest barriers to health care is poverty." Betsy added, "You got single moms trying to raise a family, their goal is to make it to tomorrow. [They] don't have any insurance and if they can get minimum wage or a little more, they can't afford insurance." The focus group participants discussed the link between using an emergency department for primary care and poverty as a leading cause of the ongoing challenges with health care access.

Finally, when asked what additional services community members believe would bridge these gaps, participant responses included co-pay assistance and specialized programs for people without insurance. These are a few recommendations that may allow uninsured or underinsured populations access to affordable, timely, and quality care. 


\section{Discussion}

While quantitative studies have focused on chronic disease in rural communities (Befort et al., 2012; Kulshreshtha, Goyal, Dabhadkar, Veledar, \& Vaccarino, 2014), ongoing research is needed to understand ways to address mental health in these communities. This study highlighted mental health and access to care disparities as acute challenges for rural communities. Addressing the mental health of rural populations is difficult given limited resources for treatment, as noted in our findings. Research has shown the potential for using online mental health services in rural populations to increase accessibility of services (Handley et al., 2014). Seventy-five percent of rural adults use the Internet (Perrin \& Duggan, 2015) and although the percentage of rural Internet use is lower than in urban areas, smart phones are widely available to a majority of people. Using the Internet to provide mental health services may present a unique set of challenges, including ensuring reliable Internet access to rural communities, improving technology literacy, and securing personal health information. However, expanding mental health services to rural populations through Internet-based methods, like telehealth and health apps could address the higher rates of suicide generally experienced in rural areas (Hirsch \& Cukrowicz, 2014).

Focus group participants' discussion of the relationship between substance abuse and mental illness echoes the Substance Abuse and Mental Health Services Administration (2015) finding that 8 million adults live with both mental illness and substance abuse challenges. The frequent coexistence of mental health and substance abuse concerns highlights the need to address these simultaneously. The Carsey Institute (Van Gundy, 2006) recommended rural communities use resources already available, such as faith-based organizations and close-knit or familial relationships to develop tailored treatment programs and provide social support to individuals in need. Community members also mentioned school systems as a resource to address mental health in students and school personnel. School systems are community assets that can be extended to others in need through weekend clinics or support groups. Finally, addressing mental health and substance abuse with evidence-based programs tailored for rural communities is a viable approach (Rural Health Information Hub, 2017).

While the ACA has helped millions of Americans gain health insurance, rural populations still face significant challenges of access to care (Avery, Finegold, \& Xiao, 2016; Blumenthal, Abrams, \& Nuzum, 2015). Though insurers reported that people who signed up for insurance were sicker than originally expected (Blue Cross Blue Shield Association, 2016), the fee assigned by the individual mandate for not having health insurance reached its highest point in 2016 (Centers for Medicare and Medicaid Services, 2016). The response cost approach to behavior change assumes people who have not purchased health insurance will do so as the penalty becomes too onerous. This will likely drive healthier individuals to exchanges and stabilize some markets as people respond to the increased cost of not purchasing health insurance. Raising the individual mandate fee further or increasing subsidies for low-income individuals are two approaches to improve access in rural Georgia.

Mental health and barriers to access emerged as prominent concerns for rural Georgia residents taking part in a routine CHNA, highlighting its value as a tool to understand the health needs of underserved communities. These findings may apply to other rural areas in the United States to inform public health efforts and future research on mental health and access to care. 


\section{Limitations}

This study was not without limitations. While attempts were made to recruit representative focus group samples, the occupations of focus group participants suggest community members of lower socioeconomic status were not sufficiently represented. Demographic information, such as age, income, and education level, was not formally collected from participants, which may limit generalizability of the findings. In addition, several high-profile leaders were present in one focus group, which may have biased results toward the perspectives of these people. To address potential bias of power imbalances that may have been present, focus group moderators attempted to solicit feedback from all participants. Finally, while nurses participated in the focus groups, no other direct care providers, such as mental health counselors or physicians participated, limiting the ability to highlight their perspectives.

The limitations of this study may be useful in framing similar research. Future research could include purposeful sampling of community members from a diverse range of backgrounds and socioeconomic status. The collection of demographic data related to income, age, and education could confirm the diversity of the sample, as well as situate the results in relation to increasing generalizability. Quantitative data collection, including follow-up surveys targeting communities of interest, to identify specific needs related to mental health, substance abuse, suicide, and access to care may also be helpful. Finally, one-on-one interviews may yield rich data and eliminate potential bias that may occur in focus groups.

\section{Contribution to Research}

This study highlighted the voices of rural community members in Georgia concerning access to care and mental health needs. These findings serve as support for ongoing rural health programs that target the key challenges outlined here. Although Georgia is the focus, these contributions may lend clarity to the complexities of access to mental health services in other rural communities.

Understanding the most salient barriers to treatment and care can improve public health efforts to reduce rural health disparities.

\section{References}

Artiga, S. (2016). Health and health coverage in the south: A data update. Retrieved from http://kff.org/disparities-policy/issue-brief/health-and-health-coverage-in-the-south-a-dataupdate/

Avery, K., Finegold, K., \& Xiao, X. (2016). Impact of the Affordable Care Act coverage expansion on rural and urban populations. Washington, DC: U.S. Department of Health and Human Services. Retrieved from https://aspe.hhs.gov/system/files/pdf/204986/ACARuralbrief.pdf

Befort, C. A., Nazir, N., \& Perri, M. G. (2012). Prevalence of obesity among adults from rural and urban areas of the United States: Findings from NHANES (2005-2008). The Journal of Rural Health, 28, 392-397. doi:10.1111/j.1748-0361.2012.00411.x

Blue Cross Blue Shield Association. (2016). Newly enrolled members in the individual health insurance market after health care reform: The experience from 2014 and 2015. Retrieved from https://bluehealthintelligence.com/engine/files/Newly_Enrolled_Individuals_After_ACA.pdf 
Blumenthal, D., Abrams, M., \& Nuzum, R. (2015). The Affordable Care Act at 5 years. New England Journal of Medicine, 372, 2451-2458. doi:10.1056/NEJMhpr1503614

Centers for Medicare and Medicaid Services. (2016). The fee for not having health insurance. Retrieved from https://www.health care.gov/fees/fee-for-not-being-covered/

Creswell, J. (2013). Research design: Qualitative, quantitative, and mixed-methods sources. Thousand Oaks, CA: Sage.

Garfield, R. (2016). The coverage gap: Uninsured poor adults in states that do not expand Medicaid. Retrieved from http://kff.org/uninsured/issue-brief/the-coverage-gap-uninsured-poor-adultsin-states-that-do-not-expand-medicaid/

Handley, T. E., Kay-Lambkin, F. J., Inder, K. J., Attia, J. R., Lewin, T. J. \& Kelly, B. J. (2014). Feasibility of internet-delivered mental health treatments for rural populations. Social Psychiatry and Psychiatric Epidemiology, 49, 275-282. doi:10.1007/s00127-013-0708-9

Hirsch, J. K., \& Cukrowicz, K. C. (2014). Suicide in rural areas: An updated review of the literature. Journal of Rural Mental Health, 38, 65-78. doi:10.1037/rmh0000018

Hughes, D., \& DuMont, K. (1993). Using focus groups to facilitate culturally anchored research. American Journal of Community Psychology, 21, 775-806. doi:10.1007/BF0094224

Internal Revenue Service. (2016). New requirements for 501(c)(3) hospitals under the affordable care act. Retrieved from https://www.irs.gov/charities-non-profits/charitable-organizations/newrequirements-for-501c3-hospitals-under-the-affordable-care-act

Kaiser Family Foundation. (2013). State Mental Health Agency (SMHA) per capita mental health services expenditures. Retrieved from http://www.kff.org/other/state-indicator/smhaexpenditures-per-capita/

Kaiser Family Foundation. (2016). Primary care health professional shortage areas (HPSAs). Retrieved from http://kff.org/other/state-indicator/primary-care-health-professional-shortageareas-hpsas/

Kulshreshtha, A., Goyal, A., Dabhadkar, K., Veledar, E., \& Vaccarino, V. (2014). Urban-rural differences in coronary heart disease mortality in the United States: 1999-2009. Public Health Reports, 129, 19-29. doi:10.1177/003335491412900105

Larrison, C. R., Hack-Ritzo, S., Koerner, B. D., Schoppelrey, S. L., Ackerson, B. J., \& Korr, W. S. (2011). State budget cuts, health care reform, and a crisis in rural community mental health agencies. Psychiatric Services, 62, 1255-1257. doi:10.1176/appi.ps.62.11.1255

Liamputtong, P. (2011). Focus group methodology: Principles and practice. Los Angeles, CA: Sage.

Maxwell, J. (2013). Qualitative research design: An interactive approach. Los Angeles, CA: Sage.

Mitchell, A. (2016). Medicaid disproportionate share hospital payments. Retrieved from https://fas.org/sgp/crs/misc/R42865.pdf

National Alliance on Mental Illness. (2015). State mental health legislation, 2015: Trends, themes and effective practices. Arlington, VA: Author. Retrieved from https://www.nami.org/AboutNAMI/Publications-Reports/Public-Policy-Reports/State-Mental-Health-Legislation2015/NAMI-StateMentalHealthLegislation2015.pdf 
Perrin, A., \& Duggan, M. (2015). Americans'Internet access: 2000-2015. Retrieved from http://www.pewinternet.org/2015/06/26/americans-internet-access-2000-2015/

Rural Health Information Hub. (2017). Evidence-based toolkits for rural community Health. Retrieved from https://www.ruralhealthinfo.org/community-health/projectexamples/evidence-levels/evidence-based

Robinson, A., Cherry, S. T., Elliott, M., Davis, M., \& Bagwell-Adams, G. (2016). Leveraging university-community partnerships in rural Georgia: A community health needs assessment template for hospitals. Journal of the Georgia Public Health Association, 5, 365-372. doi:10.21663/jgpha.5.409

Singh, G. K., \& Siahpush, M. (2014) Widening rural-urban disparities in life expectancy, U.S., 19692009. American Journal of Preventive Medicine, 46, e19-e29. doi:10.1016/j.amepre.2013.10.017

Smalley, K. B., Yancey, C. T., Warren, J. C., Naufel, K., Ryan, R., \& Pugh, J. L. (2010). Rural mental health and psychological treatment: A review for practitioners. Journal of Clinical Psychology, 66, 479-489. doi:10.1002/jclp.20688

Substance Abuse and Mental Health Services Administration. (2015). Behavioral health trends in the United States: Results from the 2014 national survey on drug use and health. Retrieved from https://www.samhsa.gov/data/sites/default/files/NSDUH-FRR1-2014/NSDUH-FRR12014.pdf

Van Gundy, K. (2006). Reports on rural America: Substance abuse in rural and small town America: A Carsey Institute Report on Rural America. Retrieved from http://scholars.unh.edu/cgi/viewcontent.cgi?article=1006\&context=carsey

Vander Weg, M. W., Cunningham, C. L., Howren, M. B., \& Cai, X. (2011). Tobacco use and exposure in rural areas: Findings from the Behavioral Risk Factor Surveillance System. Addictive Behaviors, 36, 231-236. doi:10.1016/j.addbeh.2010.11.005

Wong, S. T., \& Regan, S. (2009). Patient perspectives on primary health care in rural communities: Effects of geography on access, continuity, and efficiency. Rural and Remote Health, 9, 1142. Retrieved from http://www.rrh.org.au/home/defaultnew.asp

The Journal of Social, Behavioral, and Health Sciences is an open-access, peer-reviewed, online interdisciplinary journal focusing on research findings that address contemporary national and international issues. Its objectives are to (a) encourage dialogue between scholars and practitioners in the social, behavioral, and health sciences that fosters the integration of research with practice; (b) promote innovative models of interdisciplinary collaboration among the social, behavioral, and health sciences that address complex social problems; and (c) inform the relationship between practice and research in the social, behavioral, and health sciences.

Walden University Publishing: http://www.publishing.waldenu.edu 